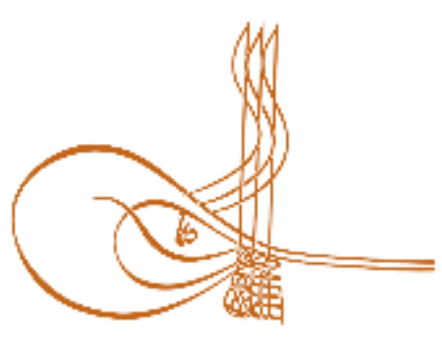

www.turkishstudies.net/social
Turkish Studies - Social Sciences

eISSN: $2667-5617$

Research Article / Araștırma Makalesi

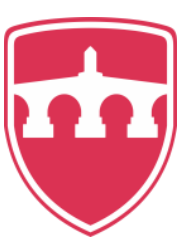

INTERNATIONAL

BALKAN

UNIVERSITY

Sponsored by IBU

\title{
Dünyada ve Türkiye’de Sürdürülebilir Turizm Kapsamında Kırsal Turizm Üzerine Kavramsal Bir Çalışma
}

\author{
A Conceptual Study on Rural Tourism in Content of Sustainable Tourism in the World and in \\ Turkey
}

\author{
Engin Derman*
}

\begin{abstract}
Tourism activities resulting from traveling for different purposes became massive at the end of XX. century. Today, tourism has been an important sociological phenomenon. Social and environmental impacts have drawn attention locally and globally, besides their economic impacts. In addition to the individual tourism movements, the increase in mass tourism activities further increased the economic, social and environmental impacts. Over time, with the effect of globalization and modernization, people's value judgments have undergone great changes and this change has also been reflected in their travel preferences. Several types of tourism have emerged as different from mass tourism such as alternative tourism and sustainable tourism which for special interests, individual preferences come to the fore and with more environmentally sensitive travel. Rural tourism has also taken its place among alternative tourism types as a sustainable tourism. Rural tourism has a positive impact on sustainable rural development particularly revealing the important role of tourism in local development. While alternative sources of income are created for rural areas through tourism, new practices in agricultural production have been developed. Rural tourism becomes a guide in solving the economic, social and environmental problems of these areas by making rural areas attractive for tourists. In this study, a conceptual research on rural tourism has been carried out and this type of tourism has been evaluated within the content of sustainable tourism. Sample applications from Turkey and different countries have been presented on rural tourism activities.
\end{abstract}

Structured Abstract: Tourism activities resulting from people traveling for different tourist purposes became mass at the end of the XX. century. Then, with the effect of globalization and modernization, value judgments have changed greatly and this change has been reflected on people's travel preferences. Several types of tourism have emerged as different from mass tourism such as alternative tourism and sustainable tourism. Rural tourism has taken its place in the literature in this context. Rural tourism has a positive impact on sustainable rural development particularly revealing the important role of tourism in local development. While alternative sources of income are created for rural areas through tourism, new practices in agricultural production can be developed. By making rural areas attractive for tourists, rural tourism can be a guide in

\footnotetext{
* Dr. Öğr. Üyesi, Akdeniz Üniversitesi Manavgat Turizm Fakültesi Turizm Rehberliği Bölümü Asst. Prof. Dr., Akdeniz University Manavgat Faculty of Tourism Department of Tour Guide Training ORCID 0000-0003-1171-6242

ederman@akdeniz.edu.tr
}

Cite as/ Atıf: Engin, D. (2020). Dünyada ve Türkiye'de sürdürülebilir turizm kapsamında kırsal turizm üzerine kavramsal bir çalışma, Turkish Studies - Social, 15(1), 237-246. https://dx.doi.org/10.29228/TurkishStudies.39427

Received/Geliş: 22 October/Ekim 2019

Accepted/Kabul: 25 February/Şubat 2020

Copyright $(C$ INTAC LTD, Turkey
Checked by plagiarism software

Published/Yayın: 29 February/Şubat 2020

CC BY-NC 4.0 
solving these problems. In this study, a conceptual research on rural tourism has been carried out and this type of tourism has been evaluated within the content of sustainable tourism.

Technology has led today's people to a sedentary lifestyle. The monotonous life brought by this lifestyle increases the desire to travel to areas where people will be more active. Rural areas are attractive places in this context. Lifestyle determines the future of people and societies. Societies and cities need a sustainable lifestyle. Tourism preferences are affected by people's lifestyles, and tourism experiences can affect people's lifestyles. In this context, rural tourism attracts attention as a type of tourism that can directly affect human life.

Rural areas are attractive areas for the modern world people and have become a tourist supply for tourists coming to the country. Now the new tourist profile is in a structure that longs for nature and wants to spend time in rural areas. Naturally, this feature of demand make it necessary to restructure the tourism supply, protect and improve the rural environment. The natural environment is the raw material of the rural tourism product. The diversity of plant and animal species in rural areas is attractive for tourists. A sustainable approach should be ensured with the awareness of conservation using nature. This situation increases the importance of rural tourism day by day within the scope of sustainable tourism.

Rural tourism, which is one of the types of tourism where local people and tourist interaction is of great importance, is a driving force in local development and plays an important role in the development of rural areas. Rural tourism has social, economic and environmental impacts at local, national and international levels. Their benefits are particularly high in terms of sustainable development. Rural tourism is an important tool in creating infrastructure for rural development and renovation of villages. Such tourism activities increase the employment opportunities of young people and women especially in rural areas. In this way, migration from rural to urban areas can be reduced.

In rural tourism practices, education of local people should be given importance. Rural people should take part in tourism activities in the countryside. A locally conscious public support should be provided, and all public and private institutions, especially local governments, should be coordinated. In order for rural tourism to be implemented within a sustainable framework, local businesses and local people should take an active role in this process. The development policies to be managed correctly in the solution of the problems of the rural areas and the subject of sustainable tourism and sustainable development should be evaluated.

Every destination has its strengths, weaknesses, opportunities and threats waiting for it. A good analysis of these will be a guide. In this way, appropriate tourism strategies can be determined. Destinations have alternative tourism resources. At this point, rural tourism can be developed in different models. This type of tourism can be evaluated in mass tourism or separately. For example, village tours can be an unforgettable experience for mass tourists. Afterwards, these tourists can travel to village tourism and become special interest tourists. A positive destination image should be provided with rural tourism products of a certain quality level. This image brings sustainability.

The management and marketing of rural tourism destinations is a very important issue. Different rural tourism types should be researched and the most suitable tourism type should be decided and encouraged. Local people are at the center of rural tourism activities as in all alternative tourism types. A strong communication network should be established with all stakeholders of rural tourism. Roadmap should be determined for common purposes. This cooperation should be planned to benefit all stakeholders. At this point, it is very important to determine the expectations of the stakeholders and to ensure coordination. Coordination can be achieved between the expectations of people in rural areas and the expectations of companies producing goods and services for the tourism sector. As a result, sustainable rural tourism models can be created. Otherwise, rural areas may experience cultural and environmental degradation through uncontrolled practices. $\mathrm{n}$ this context, it is necessary to take advantage of exemplary applications on rural tourism in the country and in the world.

While countries such as Canada, France, Italy, Spain, Germany, China and the UK make significant progress in rural tourism in the world; Turkey has not developed much yet in this market. Rural tourism practices in these countries are the sample practices for Turkey. These examples can be analyzed well to contribute to existing practices and appropriate arrangements can be made. As a result, it has been seen that

Turkish Studies - Social, 15(1) 
sustainability can be achieved in a social harmony by preserving the cultural and environmental values of rural areas with the economic power of tourism.

Keywords: Rural Tourism, Alternative Tourism, Rural Development, Sustainable Tourism

Öz: İnsanların farklı turistik amaçlarla seyahat etmelerinden ortaya çıkan turizm faaliyetleri XX. yüzyılın sonlarında kitlesel hale gelmiştir. Günümüzde turizm önemli bir sosyolojik olgu halini almıştır. Yerel ve küresel boyutta ekonomik etkilerinin yanında sosyal ve çevresel etkileri de dikkat çekmektedir. Bireysel turizm hareketleri ile birlikte kitlesel turizm faaliyetlerinin de çoğalması ekonomik, sosyal ve çevresel etkileri daha fazla artırmıştır. Zamanla küreselleşmenin ve modernleşmenin etkisiyle insanların değer yargıları büyük değişime uğramış ve bu değişim seyahat tercihlerine de yansımıştır. Artık bireysel tercihlerin öne çıktığı, özel ilgi alanlarına yönelik ve çevreye daha duyarlı seyahatler içeren alternatif turizm ve sürdürülebilir turizm gibi kitle turizminden farklı turizm türleri ortaya çıkmıştır. Kırsal turizm bu kapsamda sürdürülebilir bir turizm çeşidi olarak alternatif turizm türleri arasında yerini almıştır. Özellikle yerel kalkınmada turizmin önemini ortaya koyan kırsal turizmin sürdürülebilir kırsal kalkınma üzerine olumlu etkileri vardır. Turizm aracılığıyla kırsal alanlar için alternatif gelir kaynakları oluşturulurken, tarımsal üretimde yeni uygulamalar geliştirilmektedir. Kırsal alanlar turistler için cazip hale getirilerek, bu alanların ekonomik, sosyal ve çevresel sorunlarının çözümünde kırsal turizm yol gösterici olmaktadır. Bu çalışmada kırsal turizm üzerine kavramsal bir araştırma yapılarak bu turizm çeşidinin sürdürülebilir turizm kapsamında değerlendirmesi yapılmıştır. Kırsal turizm faaliyetleri üzerine Türkiye'den ve farklı ülkelerden örnek uygulamalar sunulmuştur.

Anahtar Kelimeler: Kırsal Turizm, Alternatif Turizm, Kırsal Kalkınma, Sürdürülebilir Turizm

\section{Giriş}

Turizm insanların farklı amaçlarla seyahat etme isteğinden doğan, gelişmekte olan ve gelişmiş toplumları birbirine bağlayan bir etkinliktir. Küreselleşen dünyada insanların değer yargıları zamanla değişime uğramaktadır. Bu değişim turizm sektörüne de yansımıştır. Artık insanlar kitlesel seyahatler yanında özel ilgi alanlarına yönelik turizm faaliyetlerini de tercih etmeye başlamışlardır. Bu sayede kitle turizminin yanında alternatif turizm ve sürdürülebilir turizm gibi içinde birçok turizm çeşidini barındıran yapılar ortaya çıkmıştır (Harrison, 2015). Kırsal turizm de bu yapılar içerisinde yerini almıştır.

Kırsal turizmin sürdürülebilir kırsal kalkınma üzerine etkileri vardır. Turizm yoluyla kırsal kesim için alternatif gelir kaynakları oluşturulabilir ve tarımsal üretim geliştirilebilir. Turizm kırsal alanların sorunlarının çözümünde yol gösterici niteliktedir. Seçilen kırsal yerleşim yerlerinin kırsal turizm kapasiteleri belirlenerek, bu alanların sürdürülebilir kalkınmasını sağlamak için turizm modelleri geliştirilmelidir (Trukhachev, 2015). Turizm kırsal alanlar için alternatif gelir kaynakları oluştururken, tarımsal üretimde yeni uygulamalar ortaya çıkarmaktadır. Kırsal alanların cazip hale gelmesiyle, bu alanların ekonomik, sosyal ve çevresel bakımdan iyileştirilmesi sağlanabilmektedir.

Sürdürülebilirlik yaşamın tüm alanlarında olduğu gibi turizm alanında da büyük önem arz etmektedir. Sürdürülebilir turizm kapsamında paydaşların sürekli fayda sağlayacağı sistemler gereklidir. Turizmin kırsal alanlarda bu ortamı gerçekleştirebilecek potansiyeli vardır. Kırsal turizmin kavramsal açıdan farklı boyutlarıyla ele alınması ve bu çerçevede dünyadaki örneklerin incelenmesi büyük önem taşımaktadır. Bu sayede Türkiye'de uygulanan kırsal turizm politikalarına yön verilebilecektir.

\section{Kırsal Turizmin Gelişimi}

İnsanların turizm faaliyetlerine katılım amaçları farklılık göstermektedir. Turizm bu bakımdan değişik nedenlerle seyahat edilmesi neticesinde ortaya çıkan bir olgudur. Bu olgu XX. Yüzyılın sonlarında kitlesel bir ivme kazanmıştır. Küreselleşmenin ve modernleşmenin etkisiyle insanların yaşam tarzları ve değer yargıları büyük ölçüde değişime uğramış, bu değişim turizm 
hareketlerine de yansımıştır. Alternatif turizm ve sürdürülebilir turizm gibi kitle turizminden farklı turizm çeşitleri ortaya çıkmıştır.

Kitle turizmi modellerine ilgi zaman içinde düşüş gösterdiğinden, küresel pazar ve sosyoekonomik çevre dikkate alınarak destinasyonlar yeniden yapılanma sürecine girmiştir (Ivars i Baidal, Rodríguez Sánchez, \& Vera Rebollo, 2013). Bu kapsamda kırsal turizm her destinasyon için farklı modellerde geliştirilebilecek niteliktedir.

Turizmin gelişiminde evrimsel yaklaşım kırsal turizm gelişiminin doğal bir değişim süreci olarak tanımlanması gerektiğini ifade eder. Arz ve talep faktörlerine göre değişik kırsal turizm gelişim teorileri önerilmektedir. Kırsal turizmin temel talep faktörleri tüketici ihtiyaç ve tercihlerine dayanır. Kırsal turizmin gelişiminde temel arz faktörleri ise yerel turizm kaynaklarına ve kırsal turizmin gelişiminde evrimsel yaklaşımın uygulanmasına dayanmaktadır. Bu sürecin doğru tanımlanması, kırsal turizm gelişim dinamiklerinin daha iyi anlaşılmasına yardımcı olacak, kırsal turizmdeki değişimler üzerinde etkili olan faktörlerin belirlenip değerlendirilmesine ve uygun yöntemlerin seçilmesine olanak sağlayacaktır (Streimikiene \& Bilan, 2015).

Kırsal turizm sadece doğa yürüyüşleri, açık hava etkinlikleri, yeme-içme gibi tarihsel, kültürel ve doğaya ait konuları kapsamaz. Yerel ve yöreye özgü içeriği ve etkinlik türleri itibariyle kadın işgücünü gerektirmekte ve kullanmaktadır. Özellikle el sanatlarına dayalı üretim biçiminin önemli faaliyet türü olması kadınları avantajlı konuma getirmektedir (Fidan \& Nam, 2012). Yerel halk ve turist etkileşiminin önemli olduğu turizm türlerinden biri olan kırsal turizm, yerel kalkınmada itici bir güç olup kırsal alanların gelişiminde önemli bir role sahiptir. Kırsal alanlar modern dünya insanı için cazip alanlar olup, ülkeye gelen turistler için de turistik arz kaynakları haline gelmiştir.

Kırsal alanlardaki turizm arzında meydana gelen değişimleri anlamak için kırsal çevre ile değişen turizm eğilimleri arasındaki ilişki incelenmelidir. Bu kavramların teorikte ve politikaların oluşumundaki önemi bu şekilde ortaya konabilir (Salvatore, Chiodo, \& Fantini, 2018). Artık yeni turist profili doğaya özlem duyan, kırsal alanlarda vakit geçirmek isteyen bir yapıya sahiptir. Doğal olarak talebin bu özelliği turizm arzını yeniden değerlendirmeyi yani kırsal çevreyi korumayı ve geliştirmeyi gerektirmektedir.

Bugün gelişmiş ülkelerde tarımsal üretim sürecinde normal ihtiyaçların dışında ve piyasa gereksinimlerine göre şekillendirilmiş, katma değeri yüksek yeni hizmetler geliştirilmektedir. İnsanların kalabalık ve kirli şehir ortamlarından kaçma ihtiyacına cevap veren rekreasyon faaliyetleri ve turizm aktiviteleri bu hizmetlerdendir. Bu sayede eski çiftlik evleri, kırsal yaşamı sevenler ve doğa hayranları için favori destinasyonlar haline gelmiştir. Günümüzde kırsal turizm; her bölgeye özgü bütünleşik kırsal kalkınma modelleri içeren, kırsal alandaki kaynakların tüketim ve üretim dengesi içinde kullanıldığg ve bölgesel paydaşların stratejik işbirliği ile hareket ettiği bir ekonomik yaklaşım haline gelmiştir (Immacolata, 2018). Bu işbirliği tüm paydaşların yararına olacak şekilde planlandığında daha başarılı sonuçlar ortaya çıkacaktır. Bu noktada paydaşların beklentilerini tespit etmek ve koordinasyonu sağlamak çok önemlidir. Kırsal alandaki insanların beklentileri ile turizm sektörüne mal ve hizmet üreten firmaların beklentileri arasında koordinasyon sağlanmalıdır. Neticede sürdürülebilir kırsal turizm modelleri oluşturmak, kırsal turizmin gelişiminde ve sürekliliğinde büyük öneme sahiptir. Aksi halde kontrolsüz uygulamalar neticesinde kırsal alanlarda kültürel ve çevresel bozulmalar ortaya çıkabilir. Bu çerçevede kırsal turizm üzerine ülkede ve dünyada yapılan örnek uygulamalardan faydalanmak gerekir.

\section{Dünyada Kırsal Turizm Uygulamaları}

Turizm ülkelerin ekonomileri üzerinde önemli etkilere sahip olan bir sektördür. $\mathrm{Bu}$ sektörden daha fazla pay almak isteyen ülkeler turizmin farklı türlerini geliştirerek turizm ürünlerini çeşitlendirme yoluna giderler. Son yıllarda bu kapsamda kırsal turizm birçok ülkenin önem verdiği alanlardandır.

Turkish Studies - Social, 15(1) 
Kırsal turizm Çin'de 20 y1lı aşkın bir süredir gelişmekte olup Çin'in politik, sosyal ve ekonomik sistemlerine uygun olarak gelişme göstermiştir. Devlet kırsal turizmi geliştirmede belirleyici bir rol üstlenmiştir. Aynı zamanda kırsal turizm ülkenin modernleşme sürecinde kırsal kalkınma için ekonomik bir araç olarak değerlendirilmiştir (Gao, Huang, \& Huang, 2009). Bu turizm çeşidi endüstride yeniden yapılanmayı, tarımsal kalkınmayı ve kırsal alanların gelişimini teşvik eden etkili bir araç haline gelmiştir (Wang et al., 2013). Kırsal turizmin iç turizm kapasitesi de çok yüksektir. Çin'deki kırsal turizme olan iç turizm talebi doğrudan ve dolaylı gelir oluşturmuştur. Çin'in bazı alt bölgelerinde iç turizm talebinin nispi gelire etkisi kayda değer bir seviyededir. Ayrıca, farklı alt bölgelerde yaşayanlar arasındaki bölgesel farklılıklar, kentsel ve kırsal halk arasındaki belirleyici faktörler turizm aracılığg ile dengelenmiştir (Yang, Liu, \& Qi, 2014). Çin'de kırsal turizm hızla gelişerek ülke turizminde önemli bir konuma gelmiştir. Kırsal turizm gelişimi ile ilgili yenilikçi modeller geliştirilmiş, bu kapsamda "Mutlu Çiftçi Evi" modeli uygulanmıştır ( $\mathrm{Su}, 2011)$.

İspanya'daki kırsal turizmin gelişiminde Avrupa politikalarının uygulanması doğrultusunda farklı kırsal turizm modelleri geliştirilmiştir. Kırsal turizmde kollektif bağlantılar ve çok paydaşlı bir sistem oluşturulmuştur. 1980'lerden sonra geleneksel deniz-kum-güneş turizmine alternatif arayışlar İspanya kırsalında turistik ürün ve hizmetlerin gelişmesini sağlamıştır. Kırsal turizmin gelişiminde kadınlara önemli rol verilmiştir. Kuzey Avrupa ülkeleri ile İspanya kırsal turizm gelişim modelleri arasında farklar bulunmaktadır (Cánoves, Villarino, Priestley, \& Blanco, 2004).

Malezya'da kırsal turizm gelişiminde yenilikçi yaklaşımlar ortaya konmuştur. Kırsal turizmin karmaşık ve dinamik yapısının kırsal turizm merkezlerinin yönetiminde hem zorluk hem de firsat olduğu belirtilmiştir (Nair \& Hussain, 2013). ABD Kuzey Dakota eyaletindeki kırsal turizm destinasyon yöneticileri turizmin faydalarını ve ziyaretçilerin amaçlarını vurgulamışlar ve destinasyon imajının misafirlerin değer algılarını doğrudan etkileyerek bölgeyi tekrar ziyaret etme isteğini artırdığını belirtmiş̧lerdir (Phillips, Wolfe, Hodur, \& Leistritz, 2013).

Orta Avrupa'nın kırsal bölgelerinde destinasyon markalaşması için uygulanabilecek emarkalaşma modeli çalışılmıştır. Avusturya'nın Karintiya bölgesi, markalaşma ve destinasyon kimliği arasındaki ilişkiyi ulusal kimliğe ilişkilendiren ve bununla bağlantılı olarak uygulayan bir örnek olarak belirlenmiştir. Çok sayıda potansiyel ziyaretçiye hitap eden sanal bir topluluk oluşturulması yoluyla uluslararası bir etki sağlayabilecek sanal bir gerçeklik oluşturulmuştur. İlk önce sanal topluluğa uygulanan bir e-marka oluşturma modeli önerisi sunulmuştur (Kavoura \& Bitsani, 2013).

\section{Türkiye’de Kırsal Turizm Uygulamaları}

Kırsal turizmin Türk turizmindeki önemi son yıllarda giderek artmaktadır. Özellikle küresel ısınma ile mücadele konusunda farkındalığın artması ile alternatif turizm arayışları insanları deniz, kum ve eğlence anlayışından dağ, göl, rafting gibi alanlara doğru itmiştir. Son zamanlarda kırsal turizm ile ilgili olarak dünyadan, yakın komşulardan ve $\mathrm{AB}$ ülkelerinden talepler artmıştır. Fransa, İtalya, İspanya, Almanya, İngiltere'deki kırsal turizm uygulamaları Türkiye için örnek uygulamalardır. Bu örnekler iyi analiz edilerek mevcut uygulamalara katkı sağlanabilir ve uygun düzenlemeler yapılabilir (Menderes \& Meslek, 2012).

Uluslararası turizm hareketlerinin yönü geleneksel kır hayatının egemen olduğu kırsal alanlara doğru bir ivme kazanmıştır. Dünyada Kanada, İspanya ve İtalya gibi ülkeler kırsal turizmde önemli ilerlemeler kaydederken; Türkiye bu pazar diliminde henüz fazla gelişememiştir. Kırsal turizm gelişiminde kuşkusuz Yerel Sivil Toplum Kuruluşlarının; yatırım, istihdam, turizm, çevre, eğitim, spor, tanıtım ve pazarlama gibi faaliyet alanlarındaki aktivitelere katılımları oldukça önemlidir (Aydın \& Selvi, 2012).

Kırsal turizm kadın istihdamı yaratması ve kadın girişimciliğini güçlendirmesi açısından sürdürülebilir kalkınmaya destek vermektedir. Edirne'de kadın girişimciler özellikle kırsal turizm 
odaklı yöresel ürün üretiminde önemli katkı yapmışlardır. Ayrıca Edirne'de kırsal turizm odaklı kadın girişimciliğin varlığı kadının sosyo-ekonomik gelişmesine destek olmuştur (Boyacıoğlu, 2014).

Bursa ilinin en eski yerleşim yerlerinden biri olan Misi köyü; doğal, tarihi ve kültürel turizm değerleri açısından zengin bir potansiyele sahiptir. Köyün ekonomik olarak canlanmasında kırsal turizm faaliyetleri önemli bir etkiye sahip olmuştur. Ancak köydeki turizm tesislerinin geliştirilerek, köylünün turizmden daha fazla yararlanması sağlanmalı, köyün tanıtımı için daha çok çaba harcanmalıdır (Güney \& Göller, 2017).

Çok zengin floraya sahip Muğla yöresi aynı zamanda pek çok endemik bitki türünü barındırmaktadır. Bölge alternatif turizm faaliyetleri için önemli bir potansiyele sahiptir. Eko turizm, çiftlik turizmi ve tarım turizmi gibi kırsal turizm uygulamalarını gerçekleştiren Pastoral Vadi Ekolojik Yaşam Çiftliği bu bölgede iyi bir örnek olarak karşımıza çıkmaktadır (Kiliç \& Kurnaz, 2010).

Isparta ilinde Eğirdir Gölü; su sporları, mağara turizmi, kuş gözlemciliği, yamaç paraşütü gibi çeşitli olanakları ve çevresindeki doğal korunan alanlar ile doğa turizmi, tarım turizmi ve kırsal turizm bakımından önemli potansiyele sahiptir. $\mathrm{Bu}$ alanda farklı girişimlerle turizm gelişimi ele alınmaktadır. Eğirdir Gölü ve çevresinin sürdürülebilir turizm çerçevesinde gelişimini sürdürmesi gerekmektedir (Korkmaz \& Nihal, 2011).

Türkiye'de kırsal turizm ekonomik, sosyal ve çevresel faydaları göz önüne alındığında ülke turizmine önemli katkı sağlayacaktır. Turizmin daha geniş zamana ve ülkenin farklı bölgelerine yayılmasında etkili olacaktır. Kırsal turizmin ülkedeki diğer turizm türleriyle entegre edilmesiyle daha dinamik bir turizm yapısı oluşturulabilir. Doğal ve kültürel mirasın korunmasında ve dünyaya tanıtılmasında önemli rolü olan kırsal turizm, sürdürülebilir turizm anlayışına en uygun turizm türüdür (Soykan, 2003).

\section{Sürdürülebilirlik Açısından Kırsal Turizm}

Kavramsal olarak sürdürülebilirlik, 1987 Brundtland Raporunda ortaya çıkmıştır. Bu belge, insanlığın bir yandan daha iyi yaşama istekleri ile diğer yandan doğanın getirdiği sınırlamalar arasında denge sağlama ile ilgilidir. Zamanla bu kavram, sosyal, ekonomik ve çevresel boyutlarda ele alınmaya başlamıştır. Sürdürülebilirlik gelecek nesillerin refahını da düşünerek mevcut ihtiyaçların tatmin edilmesini ve yeri doldurulamaz doğal kaynakların dengeli kullanımını ifade eder (Kuhlman \& Farrington, 2010). Turizm faaliyetleri de insanların refah seviyesini yükseltmek içindir. Ancak bu faaliyetler gerçekleştirilirken bireylerin, toplumların ve çevrenin yaşam kalitesinde olumlu yönde ve sürdürülebilir gelişme sağlanması dikkate alınmalıdır.

Kırsal turizm, spor turizmi ve sağl1k turizmi gibi özel ilgi turizm çeşitleri bireyin yaşam kalitesini iyileştiren, çoğu kez açık alanda aktif katılımı gerektiren etkinliklerdir. Seyahat motivasyonu ve sosyal değerler açısından işlevsel olmayı gerekli kılar. 1980'lerde ve 1990'ların başında Batı toplumları, nüfusun daha aktif, deneyime yönelik açık alan etkinliklerine belirgin bir eğilimi olduğunu fark ettiler (Hall, 1992). Günümüzün yaşam tarzı insanları daha aktif olacakları alanlara yöneltmektedir. Teknoloji insanı hareketsiz bir yaşama itmiş ve mekanikleştirmiştir. Kırsal alanlar bu bağlamda çözüm olmaktadır. Yaşam tarzı insanların ve toplumların geleceğini belirler. Toplumlar ve kentler sürdürülebilir yaşam tarzına ihtiyaç duymaktadır.

$\mathrm{Bu}$ konuda kırsal sürdürülebilir kalkınma deneyimi, toplumun duyarlılığı ve yerel yönetimlerin rolü büyük önem arz etmektedir. Kırsal alanda sürdürülebilir turizm gelişimi, yerel toplulukların gelişimine katkıda bulunacaktır. Sürdürülebilir kalkınmayı içeren kırsal turizmi geliştirmek ve yerel halkın desteğini sağlamak için stratejiler geliştirilmelidir (Amir, Ghapar, Jamal, \& Ahmad, 2015). Toplumsal çıkarlar ile ekonomik fayda arasında denge kuracak modeller ortaya konmalıdır. 
Turizmin kırsal kalkınmadaki rolü, değerli ve faydalı bir amaç olan sürdürülebilirliği içeren bir model ortaya koyabilir. Çoğunlukla, kırsal turizm; yerel ekonomiyi güçlendirmek, yeni istihdam yaratmak, bölgesel kimliği geliştirmek ve altyapıyı finanse etmek amacıyla önerilmektedir. Bölgeler, topluluklar, turizm kuruluşları ve yöneticiler turizm arzını güçlendirmek veya yeni turizm ürünleri geliştirmek için farklı stratejiler kullanırlar. Turizm destinasyonları arasında farklı gelişim yaklaşımları ve liderlik yapıları mevcuttur. Kırsal turizmin gelişiminde turizm işletmeleri ile diğer kuruluşlar arasında destinasyon yönetiminde stratejik bir işbirliği sağlanmalıdır. Böylece kırsal kalkınma stratejilerinde işbirlikçi ve özgün bir temel atılmış olur (Pröbstl-Haider, Melzer, \& Jiricka, 2014).

Turizm destinasyonları turistlerin sadakatini artırmak, yenilikçi stratejiler ve sürdürülebilir rekabet avantajı sağlamak için son derece rekabetçi pazarlarda varlığını sürdürürler. Kırsal turizmde bu sadakati etkileyen faktörler vardır. Sadakatin sürdürülebilir bir rekabet avantajı olarak önemi büyüktür. Kalite ve müşteri memnuniyeti, kırsal turizm destinasyon sadakatinde en önemli faktörlerdir (Campón-Cerro, Hernández-Mogollón, \& Alves, 2017). Sadık müşterilerin oluşturulması kriz dönemlerinde de avantaj sağlar. Kırsal turizm finansal krizlerde diğer sektörlerden daha az etkilenmektedir. Uluslararası rekabet kırsal turizmi tehdit altına alabilir. Bu durumda sürdürülebilir kırsal iç turizm bir alternatif olabilir (Sanagustín Fons, Fierro, \& Patiño, 2011). Sürdürülebilirlik için devamlı bir turizm hareketi sağlanmalıdır. Bu devamlılık kırsal alanlara özlem duyan, modern kent yaşamından sıkılan potansiyel yerli turist ile sağlanabilir. Bu şekilde iç turizm dış turizm dengesi ile sürdürülebilirlik sağlanabilir. Kırsal turizm aktiviteleri yoğun kent yaşamından sıkılan insanlar için cazip rekreasyonel etkinliklerdir. Bu rekreasyonel etkinlikler kırsal alanlarda sürekli bir hareketlilik oluşturacaktır.

Turizm, özellikle kırsal yerlerde sosyo-ekonomik kalkınma ve yoksulluğun azaltılması için önemli bir büyüme gücü olarak kabul edilmektedir. Yerel toplulukların turizmin gelişimine yönelik tutumları ve algıları sürdürülebilir turizm gelişimi için önemli göstergelerden biridir. Yerel toplulukların katılımı ve iletişim kalitesi ile sürdürülebilir kırsal turizm arasında güçlü bir ilişki vardır (Fun, Chiun, Songan, \& Nair, 2014). Yerel halk, tüm alternatif turizm çeşitlerinde olduğu gibi kırsal turizmde faaliyetlerin odağında yer alır. Kırsal turizmin tüm paydaşlarıyla güçlü bir iletişim ağı kurulmalıdır. Ortak amaçlar doğrultusunda yol haritası belirlenmelidir.

Kırsal turizmin gelişimi ve daha sürdürülebilir kırsal turizm şekilleri, turistik işletmelerin ve turistik deneyimlerin ev sahibi toplumun, çevrenin ve yerel tedarikçilerin ihtiyaçlarına uygun olmalıdır. Aynı zamanda turistlerin talep cephesinden gereksinimleri dikkate alınmalıdır. Kırsal turizm dışsal güçlerin baskısı ile gelişmemeli, yerel topluluklar ve yerel işletmeler kırsal turizme yön vermelidir (Bramwell, 1994).

Turizmin ve diğer rekreasyonel faaliyetlerin flora ve fauna üzerinde oluşturduğu sonuçlar önemlidir. Öncelikli türler ve ekosistemler tanımlanmalıdır. Turistlerin doğal çevre üzerindeki doğrudan ve dolaylı etkileri dikkate alınmalıdır (Bellan \& Bellan-Santini, 2001). Kırsal turizmin sürdürülebilirliği açısından da bu durum dikkat çekicidir. Doğal çevre kırsal turizm ürününün hammaddesini oluşturmaktadır. Kırsal alanlardaki bitki ve hayvan türlerinin çeşitliliği turistler için cezbedicidir. Bu amaçla seyahat eden yaban hayatı gözlemcileri, kuş gözlemcileri, botanik turistleri gibi özel ilgi turistleri bulunmaktadır.

\section{Sonuç ve Öneriler}

Toplumların ve kentlerin sürdürülebilir yaşam tarzına gereksinimi ortaya çıkmıştır. Günümüzün yaşam tarzı insanları daha aktif olacakları alanlara yöneltmektedir. Kırsal alanlar bu bağlamda çözüm olabilir. Turizm deneyimleri insanların yaşam tarzlarını etkileyebilir. Bu bağlamda kırsal turizm insan yaşamını doğrudan etkileyebilecek bir turizm çeşidi olarak karşımıza çıkmaktadır.

www.turkishstudies.net/social 
Turizmin gelişim evresi içerisinde, sürdürülebilir turizm kapsamında kırsal turizmin önemi günden güne artmaktadır. Bunun farkına varan ülkeler farklı uygulamalarla bu turizm çeşidini geliştirmektedir. Kırsal turizmin yerel, ulusal ve uluslararası boyutta sosyal, ekonomik ve çevresel etkileri söz konusudur. Özellikle sürdürülebilir kalkınma yönünden faydaları çok fazladır. Kırsal kalkınma yolunda altyapı oluşturmada, kırsal alanların yenilenmesinde, gençlerin ve kadınların istihdamında kırsal turizmin önemi büyüktür.

Yerel halk kırsal turizmde önemli bir rol üstlenir. Kırsalda yürütülecek turizm faaliyetlerinde kırsalın insanı yer almalıdır. Turizm bilincine sahip bir yerel halk desteği sağlanmalı, yerel yönetimler başta olmak üzere tüm kamu ve özel kuruluşlar koordine edilmelidir. Kırsal turizmin sürdürülebilir çerçevede uygulanabilmesi için yerel işletmeler gereklidir. Kırsal turizm destinasyonlarının yönetimi çok önemli bir husustur. Sürdürülebilir turizm ve sürdürülebilir kalkınma boyutlarıyla konu değerlendirilip belirli bir kalite düzeyindeki kırsal turizm ürünleri ile olumlu bir destinasyon imajı sağlanmalıdır. Bu imaj beraberinde sürdürülebilirliği getirecektir.

Doğal çevre kırsal turizm ürününün hammaddesini oluşturmaktadır. Kırsal alanlardaki bitki ve hayvan türlerinin çeşitliliği turistler için cezbedicidir. Doğayı kullanarak koruma bilinci ile sürdürülebilir bir yaklaşım sağlanabilir. Kırsal turizm kitle turizminin içerisinde ya da ayrı olarak değerlendirilebilir. Örneğin köy turları kitle turisti için unutulmaz bir deneyim olabilir. Sonrasında bu turistler köy turizmi için seyahate çıkarak özel ilgi turistlerine dönüşebilir.

Dünyada birçok ülke kırsal turizmin kırsal kalkınma sürecindeki rolünün farkına varmış ve bu konuda politikalar geliştirmiştir. Özellikle Çin bu turizm çeşidini endüstride yeniden yapılanmayı, tarımsal kalkınmayı ve kırsal alanların gelişimini teşvik eden etkili bir araç olarak kullanmıştır. İspanya bu alanda çok paydaşlı bir sistem kurmuş ve kadınlara büyük rol vermiştir. Avusturya'da kırsal turizmde internet ortamı kullanılarak yenilikçi uygulamalar gerçekleştirilmiştir.

Türkiye'de kırsal turizm uygulamaları münferit girişimlerle sınırlı kalmış, devlet politikasına dönüşememiştir. $\mathrm{Bu}$ alanda planlama, yönlendirme ve teşvikler gerekmektedir. Anadolu'nun tarihi, kültürel ve coğrafi yapısı göz önüne alındığında Türkiye zengin bir kırsal turizm potansiyeline sahiptir. Kırsal alanların kültürel ve çevresel yönden özgün değerleri korunarak, turizmin ekonomik gücü ile sosyal bir uyum içerisinde sürdürülebilirlik sağlanabilecektir.

\section{Kaynakça}

Amir, A. F., Ghapar, A. A., Jamal, S. A., \& Ahmad, K. N. (2015). Sustainable Tourism Development: A Study on Community Resilience for Rural Tourism in Malaysia. Procedia - Social and Behavioral Sciences. https://doi.org/10.1016/j.sbspro.2014.10.217

Aydın, E., \& Selvi, M. S. (2012). Kırsal Turizmde Yerel Sivil Toplum Kuruluşlarının Rolü: Düzce İli Örneği. Uluslararası Sosyal ve Ekonomik Bilimler Dergisi.

Bellan, G. L., \& Bellan-Santini, D. R. (2001). A review of littoral tourism, sport and leisure activities: Consequences on marine flora and fauna. In Aquatic Conservation: Marine and Freshwater Ecosystems. https://doi.org/10.1002/aqc.461

Boyacıoğlu, E. Z. (2014). Kırsal Turizmde Kadın Girişimciliği : Edirne Örneğ. Uluslararası Sosyal ve Ekonomik Bilimler Dergisi.

Bramwell, B. (1994). Rural tourism and sustainable rural tourism. Journal of Sustainable Tourism. https://doi.org/10.1080/09669589409510679

Campón-Cerro, A. M., Hernández-Mogollón, J. M., \& Alves, H. (2017). Sustainable improvement 
of competitiveness in rural tourism destinations: The quest for tourist loyalty in Spain. Journal of Destination Marketing and Management. https://doi.org/10.1016/j.jdmm.2016.04.005

Cánoves, G., Villarino, M., Priestley, G. K., \& Blanco, A. (2004). Rural tourism in Spain: An analysis of recent evolution. Geoforum. https://doi.org/10.1016/j.geoforum.2004.03.005

Fidan, F., \& Nam, D. (2012). Kırsal turizmde yeni dinamikler: Kadın girişimciler-Taraklı örneği. KMÜ Sosyal ve Ekonomik Araştirmalar Dergisi.

Fun, F. S., Chiun, L. M., Songan, P., \& Nair, V. (2014). The Impact of Local Communities' Involvement and Relationship Quality on Sustainable Rural Tourism in Rural Area, Sarawak. The Moderating Impact of Self-efficacy. Procedia - Social and Behavioral Sciences. https://doi.org/10.1016/j.sbspro.2014.07.274

Gao, S., Huang, S., \& Huang, Y. (2009). Rural tourism development in China. International Journal of Tourism Research. https://doi.org/10.1002/jtr.712

Güney, D., \& Göller, V. (2017). Kırsal Turizm Konusunda Yerel Halkın Yaklaşımının Belirlenmesi: Misi Köyü Örneği. Turizm Akademik Dergisi.

Hall, C. M. (1992). Adventure, sport and health tourism. Adventure, Sport and Health Tourism.

Harrison, D. (2015). Development theory and tourism in developing countries: What has theory ever done for US? International Journal of Asia-Pacific Studies.

Immacolata, V. (2018). Agriculture, rural tourism and circular paradigm. Quality - Access to Success.

Ivars i Baidal, J. A., Rodríguez Sánchez, I., \& Vera Rebollo, J. F. (2013). The evolution of mass tourism destinations: New approaches beyond deterministic models in Benidorm (Spain). Tourism Management. https://doi.org/10.1016/j.tourman.2012.04.009

Kavoura, A., \& Bitsani, E. (2013). E-branding of rural tourism in Carinthia, Austria. Tourism.

Kiliç, B., \& Kurnaz, A. (2010). Alternatif Turizm ve Ürün Çeşitliliği Oluşturmada Ekolojik Çiftlikler: Pastoral Vadi Örneği. İsletme Araştırmaları Dergisi.

Korkmaz, M., \& Nihal, S. (2011). Eğirdir Gölü ve çevresinde turizm gelişiminin sürdürülebilirliği üzerine değerlendirmeler. SDÜ Orman Fakültesi Dergisi.

Kuhlman, T., \& Farrington, J. (2010). What is sustainability? Sustainability. https://doi.org/10.3390/su2113436

Menderes, A., \& Meslek, N. (2012). Top 5 Countries in The EU's Rural Tourism and Rural Tourism in Turkey, 14(23), 39-46.

Nair, V., \& Hussain, K. (2013). Conclusions: Contemporary responsible rural tourism innovations: What are the emerging contemporary rural tourism innovations and how are they enhancing responsible tourism practices in Malaysia? Worldwide Hospitality and Tourism Themes. https://doi.org/10.1108/WHATT-04-2013-0023

Phillips, W. J., Wolfe, K., Hodur, N., \& Leistritz, F. L. (2013). Tourist Word of Mouth and Revisit Intentions to Rural Tourism Destinations: A Case of North Dakota, USA. International Journal of Tourism Research. https://doi.org/10.1002/jtr.879

Pröbstl-Haider, U., Melzer, V., \& Jiricka, A. (2014). Rural tourism opportunities: Strategies and requirements for destination leadership in peripheral areas. Tourism Review. https://doi.org/10.1108/TR-06-2013-0038 
Salvatore, R., Chiodo, E., \& Fantini, A. (2018). Tourism transition in peripheral rural areas: Theories, issues and strategies. Annals of Tourism Research. https://doi.org/10.1016/j.annals.2017.11.003

Sanagustín Fons, M. V., Fierro, J. A. M., \& Patiño, M. G. y. (2011). Rural tourism: A sustainable alternative. Applied Energy. https://doi.org/10.1016/j.apenergy.2010.08.031

Soykan, F. (2003). Kırsal turizm ve türkiye turizmi için önemi. Ege Coğrafya Dergisi.

Streimikiene, D., \& Bilan, Y. (2015). Review of rural tourism development theories. Transformations in Business and Economics.

$\mathrm{Su}$, B. (2011). Rural tourism in China. Tourism Management. https://doi.org/10.1016/j.tourman.2010.12.005

Trukhachev, A. (2015). Methodology for evaluating the rural tourism potentials: A tool to ensure sustainable development of rural settlements. Sustainability (Switzerland). https://doi.org/10.3390/su7033052

Wang, L. en, Cheng, S. kui, Zhong, L. sheng, Mu, S. lin, Dhruba, B. G. C., \& Ren, G. zhu. (2013). Rural tourism development in China: Principles, models and the future. Journal of Mountain Science. https://doi.org/10.1007/s11629-013-2501-3

Yang, Y., Liu, Z. H., \& Qi, Q. (2014). Domestic tourism demand of urban and rural residents in China: Does relative income matter? Tourism Management. https://doi.org/10.1016/j.tourman.2013.05.005 